\title{
The Catalog-A Finding List?
}

W

E ARE TOLD that as reference librarians, with responsibility to make our views known to those concerned with code revision, we should examine the alternative functions of the catalog. These alternatives, briefly stated, are between the catalog as a finding list and the catalog as a reference or bibliographic tool.

The manner in which the problem is postulated reminds me of the history of the so-called "mind-body problem." Philosophers at least as early as Aristotle were concerned with the relationship between the mind and body. They knew that there was a relationship, but were defeated in their efforts to explain adequately how the material body could affect the non-material mind and vice versa. As long as the question was posed in a manner that assumed the essential difference between mind and body, there could be no effective understanding. Only when scientific reason proceeded to assume that body and mind were the same (mind as an emergent phenomenon of body in a particular state of organization) was the necessary basis secured for modern scientific investigation in this field.

Although this is a glaring over-simplification of a complex problem, a parellel may be drawn to the problem offered to the reference librarian. $\mathrm{He}$ is asked to assess the relationship between the cata$\log$ as a finding list and as a reference tool. The essential difference in the nature of the two things is assumed. Is this assumption justified?

Mr. Dubester is chief of the General Reference and Bibliography Division, Library of Congress.

\section{Problems of Reference Librarian}

The reference librarian has faced the results of rather practical problems which have confronted the administrators of large libraries. Growing cataloging costs and growing costs of maintaining large and complex catalogs have required an examination of present practices and a development of hospitality to changes in the accepted way of doing things. The suggestions that have been offered at one time or another would accomplish one or several changes. They would simplify cataloging by limiting the information placed on the catalog entry or by limiting the research invested in securing information for the catalog entry; or they would reorganize the catalog in the direction of eliminating entries. Such elimination might be through dividing the catalog so that the new parts would be less complex than the structure of the prior whole, or through the withdrawal of homogenous elements with the further intention of presenting the withdrawn portions in book form; or through combinations and variations of these processes.

Invariably, in the face of these suggestions, the reference librarian confronts a difficult situation. He or she has accumulated experience which has demonstrated the usefulness of some of the information which would henceforth be systematically eliminated from the catalog card or from the catalog. He or she has experience with the inner relationships of this socalled "complex structure" which has led to the identification of materials that would otherwise have been missed. The reference librarian is not in a good position to quantify this experience and to reduce it to the form of a statistical expression. The evidence is usually mar- 
shalled in anecdotal form and as such is subjective, impressionistic, biased, and generally unreliable in this era which places a premium on concrete evidence and statistical fact.

Although a considerable literature has evolved concerning approaches toward the resolution of these questions, the essential problem has not been altered appreciably, nor have there been any very significant tests through practical implementation. Significant variations in the structure and in the organization of catalogs and in cataloging practices are found in special libraries and documentation centers with their collections of special types of materials, and their obligation to serve a special public with predetermined needs and interests. The general research library, with interests in the arts, sciences, and humanities has remained essentially unaffected. The general research library has, however, accepted the challenge posed by the enormous influx of published matter. It has accepted the need to explore the possibility of asserting radical changes in patterns that are now old enough to be suspect by a new generation of librarians who are stimulated by the developments in mechanization and in the ideational content of the broad complex we call "documentation."

Nevertheless, the reference librarian, in his day-by-day work of serving a general public and assisting in providing access to collections embracing broad fields of knowledge, is holding firm in insisting on the value, merit, and usefulness of the traditional approaches. $\mathrm{He}$ is all but inarticulate, however, in his efforts to convince those proposing changes and choices that the old approaches - the full cataloging, the dictionary arrangements-have not lost their essential validity. There is good reason to believe that any attempt to dismiss the position of the reference librarian as a narrow effort to forestall the inevitable march of prog- ress will itself prove to be shortsighted in its wider implications.

\section{Further Questions}

Some of the difficulties in rationalizing the arguments, the different interpretations and analysis, and the proposals for choice or change, may be dispelled if further questions are raised as to the exact meanings and implications of the terms "finding list" and "reference tools" which are used as if all can agree on their definitions. In the context of the arguments, these terms are used in apparent opposition, as if they represent different things and as if the proposed choice between them were a real and actual choice. The reference librarian may properly argue, however, that the distinction is more apparent than real, and that the choice is spurious rather than actual.

The lack of choice becomes rather obvious when it is realized that with respect to the function of the catalog as a finding list the reference librarian has no choice whatsoever. Whatever else it may be or may become, the library's catalog must serve to locate materials in a library's collection. If it does not do this, it has only little or occasional value in providing access to the collections.

Thus, there is an immediate qualification to the choice that is offered. The catalog must be a finding tool, and if this is accepted one half of the choice is removed. What then remains of the other half, the function of the catalog as an effective bibliographic or reference tool? It is at this point that we might assert categorically that in order to serve its finding purpose, the catalog must be a bibliographic and reference tool as well; or alternatively, that only insofar as the cata$\log$ provides bibliographic or reference information can it function adequately as a finding tool. This can be demonstrated by a closer examination of the meaning of the term "finding tool."

Does "finding" mean merely to locate an entry in the catalog when the basic in- 
formation required for the proper identification of the item (in accordance with established cataloging practices) is available? Does the finding function of the catalog also include the responsibility to aid in the identification of the item as a precondition of its location in the collections?

If the first of these alternatives is accepted as defining the finding function we may examine some interesting implications. We may ask, for example, what aspects of the conventional cataloging elements are basic and indispensable for finding. The author entry? Yes, it is indispensable. The title? It, too, is indispensable. The edition, imprint, collation, series and bibliographic notes, etc.? Apparently we can do without these, as did the editor of the New York State Library's Checklist of Books and Pamphlets in the Social Sciences, ${ }^{1}$ which was designed solely with the finding purpose uppermost. It means, in fact, that, in its reductio ad absurdum, only the author and title have to be known in the manner in which they are entered in the catalog for the desired work to be findable. This, of course, only pinpoints the difficulty which is the common bond of all reference librarians. The author may be known but not the title, or vice versa. The author may be known in a form other than that in which it is entered in the catalog. The work may not be known by author or by title, but rather in its series or other relationships.

The experienced reference librarian can multiply these examples in kind and in quantity. We know that not infrequently the problem of locating a work is not one of having incomplete information but rather one of having incorrect information. In such instances, the ob-

\footnotetext{
1 The Checklist of Books and Pamphlets in the Social Sciences, a 142-page, two-columned list, aiming at a title per line, was produced in 1956 by means of I.B.M. punched card techniques at the New York State Library punched card techniques at the New York State Library
in Albany. It provides author, title, imprint date, and in Albany. It provides author, title, imprint date, and class number. The compilation was designed with by that library, and no criticism is here intended or implied.
}

vious prior task to finding is the task of identification. Furthermore, the librarian's task is very frequently one of selection according to practically unlimited criteria. This task is also one which requires identification prior to location and normally utilizes some or all of the elements of the conventional fullycataloged entry.

All this is to say that to divorce identification, which entails the exploitation of the total results of the skilled cataloger's enterprise, from finding is to erect an artificial distinction which does not apply in practice.

To argue that the published bibliography can replace the bibliographic function provided by the catalog, in the broadest sense of such proposal, is to ignore the fact that bibliographic compilations tend to rely on the very tools that are to be modified. With rare exceptions, bibliographies are compiled in libraries -in libraries with extensive collections and with catalogs which represent these collections in consideration of the different types of approaches that are usually made to the materials. If libraries were to limit their cataloging on the assumption that the finding function is the only proper function of the catalog, ignoring the relationship between identification and finding, and assuming a permanent reliance on published bibliographies, it may be realized to the sorrow of the library profession that a rather circular process has been engendered which denies the information for the development of the tool that is expected to serve in place of the information denied.

The reference librarian must also cautiously investigate the implications of any decision which in the first place accepts the distinction between the finding and the reference functions of the catalog, and secondly asserts that the first has a higher order of preference than the second. It should be recalled that, in its present setting, the problem is raised and 
stimulated by the attempts to secure catalog code revision. Code revision, for the present, is mainly concerned with the A.L.A. Cataloging Rules-Author and Title, but the recombining of rules for description with rules for author and title entry is indicated for the future. Only in the farther reaches of this enterprise will reconsideration of the rules of descriptive cataloging or a code for subject cataloging become matters of the moment. We may assume that eventually the latter rules will require renewed attention for the very same reasons that led to revision of the rules for author and title entry, including reasons based on economy, on the need for standardization, and on the need to make practices conform to changes in the environment in which the rules are applied.

If the reference librarian concedes that bibliographic information provided in the code for author and title entries is not an aspect of finding materials in the collections of a library through its cata$\log$, the stage will have been set for the argument that such bibliographic information is dispensable in the descriptive and subject analysis of this material.

In the foregoing we have mentioned the choice confronting the reference librarian. No attention has been paid to the most prominent user of the library's catalog-the reader. The reader is not only inarticulate, he is anonymous. $\mathrm{He}$ may or may not experience problems in his use of the catalog. If he does, he may or may not seek help from the reference librarian. Conventionally, we have permitted the reference librarian to represent the reader, assuming that there is an essential identity between the two. This assumption, like so many others that are made in this broad problem area, is not entirely warranted. The reference librarian, at least today, approaches his service and work with certain academic preparation which is soon complemented by actual experience in the use of the catalog which helps in coping with the vagaries and the complexities that have so far been an inescapable adjunct of reference work. The reader is an indeterminate entity. In the college and university library he may be a graduate or undergraduate student, a member of the faculty, a visiting scholar. In the general large public or research library (and this group frequently includes our large university libraries) the reader may be a scholar, a layman pursuing a variety of individual interests, or even a burdensome crackpot. In fact, the distinction that is to be drawn among the larger libraries is becoming more diffuse, and all tend to serve many of the same elements with difference in concentration and official emphasis. A reader who is a scholar and specialist in a given field may use the library for purposes entirely unconnected with his specialization and may therefore have all the attributes of the undergraduate student or layman. The objective appraisal of reader behavior is coming to the forefront of recognized needs. The Library of the Massachusetts Institute of Technology has exploited the techniques of "operations research" recently to study reader behavior. Perhaps of more immediate consequence is the Catalog Use Survey sponsored by the American Library Association, which uses a standardized questionnaire to itemize reader behavior at the catalog, discriminating between subject and author approaches, but permitting analysis of their relationships; and also discriminating between the approaches to the catalog in terms of their success and failure. The findings of such studies need not necessarily agree with the less objective appraisals by the reference librarian. At present, they are first approaches and may correctly be considered as the basis for further exploration in detail. Their importance, in long range extension, is not to be underestimated. It would be hazardous, however, to sud- 
denly shift grounds and to assume that the objective evidence of preliminary studies of reader behavior can justify courses of action questioned by the collective experience of reference librarians. This, of course, assumes an essential disagreement, which may be not at all the case.

One final aspect of the problem of choice between the catalog as a finding and as a bibliographic or reference tool requires attention. It has been posited that the distinction between the catalog as a finding tool against its use as a reference and bibliographic tool is not a realistic or a practical one. If this is accepted, what are the consequences of this view on the scope and structure of the catalog, and more immediately on the problem of code revision?

We would like to approach an answer in a rather roundabout manner. The reference librarian is necessarily faced with the fact that there is a direct relationship between the amount of information in the catalog and the ease of his work. This is true whether the reference librarian works only with readers, or in addition replies to written reference inquiries, compiles bibliographies, or undertakes research projects. Stated in another fashion, it is the common experience of reference librarians that the larger the number of approaches to a work in a catalog, the easier is the task of the reference librarian. Therefore, any development in the code for author and title entry which limits the information on the catalog card, or which reduces the approaches to a work, would appear to hinder rather than to serve the reference librarian in identifying and locating materials through the use of the catalog.

Even granting this, we know that the reference librarian is one of many members of a larger library team, and that many functions besides that of reference depend on the catalog for their effective performance. Code revision will affect the entire staff, not merely the reference librarian. It is this which has to be considered by the entire library profession, of which the reference librarian is merely one component.

With this in mind, it may be suggested that a revised code should be one that has as its goal the ideal catalog. It may provide for economies, insofar as such economies are of a type which a significant number of libraries are likely to adopt; but it should not let the desire for economy become a limiting factor on the code itself. We must remember that regardless of how pressing the problems are which have caused library administrators to examine their present practices, there still remain libraries with ability to limit their acquisitions within prescribed boundaries and with adequate staff to catalog current acquisitions. Such libraries will not be served by rules oriented to those libraries seeking curtailment in the quality of the cataloging effort in order to achieve quantity. Even the latter will in most cases reserve certain types of materials for ideal cataloging in perfect recognition of the lasting importance of this type of record for long-term reference work. It would then behoove the individual library to take administrative steps designed to adapt the code as revised to their particular situation. Certainly this has been the normal state of things in libraries whether we wish to recognize the fact or not.

It is this writer's understanding that the original impetus toward code revision was prompted by the recognition of a need to rationalize the rules as they have developed, to bring together related rules which are now scattered throughout the body of the present code, to improve rules for entering corporate bodies and societies and institutions, and in general to develop a code with a coherent body of principles and a reduced emphasis on individual rules for all pos-

(Continued on page 159) 
To perpetuate the memory of Mrs. Walker, the Board of the Family-School Alliance of the University Elementary School has established the Winifred Walker Memorial Fund for scholarships in the field of children's librarianship. Contributions may be sent to the chairman, Mrs. Blanch DeChene, in care of the Family-School Alliance, University Elementary School, University of California, Los Angeles 24.

\section{ACRL Foundation Grants Program}

(Continued from page 154)

REMINGTON RAND

Bard College, Annandale-Hudson, N. Y. 200

Centre College of Kentucky, Danville,

Ky. .................... 200

Clarkson College of Technology, Pots-

dam, N. Y. ............... 400

George Pepperdine College, Los Angeles, Calif. ................ 400

Grand Canyon College, Phoenix, Ariz. 300
Hiram College, Hiram, Ohío ...... 300

Immaculata College, Immaculata, Pa. . 250

King's College, Wilkes-Barre, Pa. . .. 500

Marymount College, New York, N. Y. . 200

Meredith College, Raleigh, N. C. .... 400

Nasson College, Springvale, Me. ..... 400

Park College, Parkville, Mo. ....... 300

Roosevelt University, Chicago, Ill. ... 400

Salem College, Salem, W. Va. ...... 500

\section{News from the Field}

\section{(Continued from page 156)}

The University of Kansas Library has announced the Taylor Student Book Collection Contest for spring 1957. Through the generosity of Mr. and Mrs. James W. Taylor of Kansas City, Mo., prizes totaling $\$ 100$ will be awarded for the best collections entered by any KU student. Mrs. Taylor (herself an enthusiastic collector of H. L. Mencken) and Mr. Taylor hope to promote recognition of the importance of the amateur collector and to encourage the early development of book collecting interests among KU students.
Saint Louis University has become the eighteenth member of the Midwest Inter-Library Corporation. Thus the important research collections of Saint Louis University, including the notable Vatican manuscripts microfilms, are added to the resources of the present MILC members to form an impressive group of library materials for research in the Middle West. James V. Jones, director of libraries of Saint Louis University, will represent his institution of the MILC Advisory Committee of Librarians.

\section{The Catalog-A Finding List?}

(Continued from page 111)

sible variations which authorship is capable of producing. This revision would also provide the basis for eventual international agreement on rules of entry, including and even extending beyond the Anglo-American fraternity. This is an eminently worth-while goal. It can be achieved through the cooperate enterprise of librarianship without creating artificial distinctions and hurdles for the reference librarian who is always dependent upon the work of the cataloger and the code upon which the cataloger bases his decisions. The achievement of the stated purposes will of and by itself produce improvements and economies, and administrative judgment can further secure these gains in the individual library situation. 